13. Костылева А.А. Комплексный анализ глиняной обмазки с поселения Сертея II, слой $\alpha / /$ Каменный век. От Атлантики до Пацифики. Замятнинский сборник. СПб., 2014. Вып. 3. С. 340-359.

14. Hulthén B. On ceramic technology during the Scanian Neolithic and Bronze Age. Stockholm, 1977.

15. Лакіза В.Л. Старажытнасці позняга неаліту і ранняга перияду бронзавага веку Беларускага Панямоння. Мінск: Беларус. навука, 2008. 343 с.

16. Свэшніков І.К. Історія населення Передкарпаття, Поділля і Волині в кінці III - на початку II тысячоліття до нашої ери. Київ, 1974. 208 с.

17. Зальцман Э.Б. Поселения культуры шнуровой керамики на территории Юго-Восточной Прибалтики. М., 2010. 312 c.

18. Grömer K., Kern D. Technical data and experiments on corded ware // Journal of Archaeological Science, 37. 2010. P. 3136-3145.

19. Hald M. Ancient Danish textiles from Bogs and Burials // Publications of the National Museum. Archaeological-Historical Series. Vol. XXI. 1980. P. 125-128.
20. Хрусталева И.Ю., Ткач Е.С. Возможности применения магнитометрического анализа на памятниках эпохи неолита лесной зоны (Смоленская область, Россия) // Новые исследования по археологии стран СНГ и Балтии. Материалы школы молодых археологов. М., 2011. С. 114-124.

21. Ozols J. Ursprung und Herkunft der Zentalrussischen Fatjanowo-Kultur. Berlin, 1962.

22. Krzak Z. The Złota Culture. Wrocław, 1976. 254 p.

23. Клейн Л.С. Теоретический словарь археологии. Донецк, 2014. 279 с.

24. Кривальцевич Н.Н. К проблеме культурного взаимодействия населения культуры со шнуровой керамикой Верхнего Поднепровья и Восточной Прибалтики // Древности Подвинья: исторический аспект. СПб., 2003. С. 112-118.

25. Neustupny E. Prehistoric migration by infiltration // Archeologicke rozledy. Praha, 1982. XXXIV (3). P. 278-293.

\title{
CERAMIC VESSELS WITH CORD ORNAMENTATION ON THE NORTH-WEST RUSSIA (BASING ON THE MATERIALS OF THE LAYER $\alpha$ SETTLEMENT SETREYA II)
}

\author{
(C) 2016
}

E.S. Tkach, junior researcher of the Department of Paleolithic

Institute of History of Material Culture of the Russian Academy of Sciences, Saint-Petersburg (Russia)

Abstract. For the last decades interest to the Corded Ware cultures has increased. This is connected with the opening of new settlements and with new data, obtained by the latest scientific methods (C-14, aDNA). Territory of the Lovat'-Dzvina interfluve is a border zone along the Western Dzvina (Daugava) river. Here we could trace the interaction between different cultural traditions of the ancient population. One of the settlements, where this is possible, is layer $\alpha$ of the settlement Serteya II. This is a multilayer settlement and archaeological material here included vessels from the different periods - from Early Neolithic to the Iron Age. 28 vessels are associated with Corded Ware cultures. They are distinguished by the ornamentation method - cord impressions use on pottery. Their characteristic feature is also an admixture of grass in the dough and patches use during vessels making. Specific to the Corded Ware cultures pottery forms (amphora and beakers) were also found. Analogies of these types can be found in Poland, the Baltic States and in the materials of Fatyanovo culture. Their discovery among studied settlement may be regarded as an import and indicates a possible infiltration of the Corded Ware cultures inhabitants on the Lovat'-Dzvina interfluve in Late Neolithic.

Keywords: Corded Ware and Battle axes cultures; Late Neolithic; Early Bronze Age; North-West Russia; Western Dzvina (Daugava); Lovat'-Dzvina interfluve; corded ornamentation; morphology; technology of making pottery; cultural traditions; infiltration; migrations; mixing.

УДК 902.01

\section{ТРАДИЦИИ ФОРМООБРАЗОВАНИЯ И ОРНАМЕНТАЦИИ КЕРАМИКИ НАСЕЛЕНИЯ ЭПОХИ БРОНЗЫ СЕВЕРНОЙ ЧАСТИ ВОЛГО-УРАЛЬЯ: О МЕСТНОЙ ЛИНИИ РАЗВИТИЯ}

(C) 2016

О.Д. Мочалов, доктор исторических наук, ректор, профессор кафедры отечественной истории и археологии Самарский государственный соџиально-педагогический университет, Самара (Россия)

Аннотация. В формировании керамических комплексов эпохи бронзы всегда принимали участие местные волго-уральские группы населения, но их вклад в генезис последующих традиций был неравноценным, различным по масштабам и значимости и неравномерно проявлялся в сферах технологии, формообразовании и декорировании. Все это отражалось в локальной специфике регионов и конкретных памятников. Соседнее население, в первую очередь степное, периодически вовлекалось в систему взаимодействия, но направления и интенсивность контактов корректировались в зависимости от сочетания самых разнообразных факторов и особенностей исторических периодов. Взаимодействие местных и соседних, в основном культурно близких групп, усложнялось дальними связями, которые фиксируются в резких изменениях некоторых традиций, дестабилизации навыков формообразования или появлении черт, совершенно несвойственных для предшествующего времени, что способствовало выработке новых культурных стандартов. Вовлечение населения северной части Волго-Уралья в систему дальних связей отражено в периодическом распространении его традиций 
на значительные расстояния, что особенно рельефно проявляется в эпоху ранней, а затем поздней бронзы. В статье, кроме традиционных типологических, представлены результаты применения специальных методов анализа керамики: выявление естественной структуры форм, структурный анализ орнамента, установление степени близости керамических комплексов.

Ключевые слова: Волго-Уральское междуречье; бронзовый век; лесостепь и север степи; форма и орнамент керамики; типология; естественная структура форм; навыки формообразования; структурный анализ орнамента; степень близости; ямная культура; полтавкинская культура; потаповский тип; абашевская культура; синташтинская культура.

При изучении формирования керамических комплексов археологических культур эпохи бронзы Волго-Уралья отмечаются как местные, так и пришлые компоненты, даже из весьма удаленных территорий. Установлено, что на формообразование и орнаментику керамических комплексов эпохи бронзы оказывали как прямые, так и опосредованные воздействия, южные, юго-западные контакты, связи с культурами пережиточного энеолита лесной зоны ПоволжьяЗаруалья, с населением Кавказа, Средней Азии, Сибири, которые иногда выступали значительными «катализаторами» в сложении культур [1, с. 200-251]. Цель данной работы - продемонстрировать основные результаты анализа местных истоков в генезисе форм и декора керамических комплексов культур: ямной среднего Поволжья и Приуралья, средневолжской полтавкинской, «позднекатакомбной» степного Приуралья, абашевской Приуралья, памятников потаповского культурного типа, синташтинской Приуралья, срубной, алакульской Приуралья. Преобладающая часть керамики указанных культур хорошо известна и опубликована в многочисленных работах исследователей Самары, Уфы, Оренбурга и Орска. Изучение керамических традиций лесостепного - севера степного Волго-Уральского междуречья с использованием комплекса методов (естественная структура форм, навыки формообразования гончаров, структура и технология декора, типология, степень близости, количественное соотношение признаков) [2, с. 5-22; 3 , с. $25-60 ; 4$, с. $3-8 ; 5$, с. $30-82 ; 1$, с. $4-36]$ и с учетом данных хронологии, позволили установить динамику их изменений и характер взаимосвязи в Заволжье и в Приуралье (рис. 1, 2).

При формировании культур местные традиции не исчезали, а, как правило, нередко преобладая, участвовали в их сложении, невзирая на смешение различного населения. Смешение и контакты как внутри изучаемых групп, так и внешние имели место на протяжении всего бронзового века, но интенсивность и направленность их была различной и зависела от суммы факторов. Усиление внешних связей стимулировало сложение традиций гончарства новых культур, изначально вызванное контактами населения внутри самого Волго-Уралья. В обобщенном виде роль местных традиций выглядит следующим образом.

В сложении керамических комплексов ямной культуры участие местных энеолитических традиций очень невыразительно. Вероятен перенос в основном сложившихся стандартов из степного Поволжья, тесно связанных с репинскими древностями и усложненных синкретическими группами позднего энеолита. Степные районы Средневолжья также, видимо, входили в ареал сложения ямных керамических традиций. По мере освоения ямным населением лесостепного Заволжья и степного Приуралья местные энеолитические традиции иногда «наслаивались» на существующие в качестве вторичных, более поздних компонентов.

Полтавкинский керамический комплекс напрямую связан с ямным Волго-Уралья, что подтверждают и данные технологии. Его окончательное формирование было усложнено сильными инокультурными воздействиями с юго-запада и севера. Вопрос доживания полтавкинских традиций до позднего бронзового века остается открытым.

Для абашевской керамики Приуралья, в целом средневолжского лесного происхождения, зафиксировано участие местного позднеэнеолитического компонента и культур «гребенчатого геометризма» Урало-Казахстанского региона. На развитом этапе культуры имело место взаимодействие с потаповскими и синташтинскими традициями. Однако влияние абашевских канонов на них не было абсолютно определяющим. Абашевская керамика сама испытала значительное влияние синташтинско-потаповских гончаров на позднем этапе развития культуры.

Керамика различных памятников эпохи средней бронзы степного Приуралья (позднекатакомбных по В.В. Ткачеву) [6, с. 228-257] поликультурна и, возможно, неоднородна хронологически. Катакомбные традиции в чистом виде не представлены. В разных памятниках присутствуют черты абашевской, полтавкинской, волго-донской, северокавказской, вольсклбищенской и синташтинской культур. Имело место смешение разнородных традиций, а некоторые были привнесены в готовом виде.

Потаповский керамический комплекс сформировался на основе полтавкинских и, видимо, волгодонских традиций при участии южноуральских абашевских и синхронных синташтинских, формирующихся параллельно. Не исключено, что в сложении керамики «потаповки» и «синташты» очень важную роль сыграли транскультурные близкие по происхождению постъямные группы населения, представленные в различных культурах степи - юга лесосотепи Поволжья, Подонья и Предкавказья, изготавливающие определенные типы «елочной» керамики и керамики, орнаментированной треугольниками. Ярко представлена группа, отражающая переход к срубным и андроновским стандартам. Керамика западных синташтинских памятников близка потаповской, но менее выражены полтавкинский и абашевский компоненты. Оснований для их четкого хронологического разделения с потаповскими нет. Сложение этой группы, как и всей «синташты», связано как с местными волго-уральскими и зауральскими культурами, так и с вероятным влиянием традиций Средней Азии и Кавказа, которые являлись «катализатором» некоторых изменений в формах, реже в декоре. 
Ветлянский тип (ранняя срубно-алакульская)
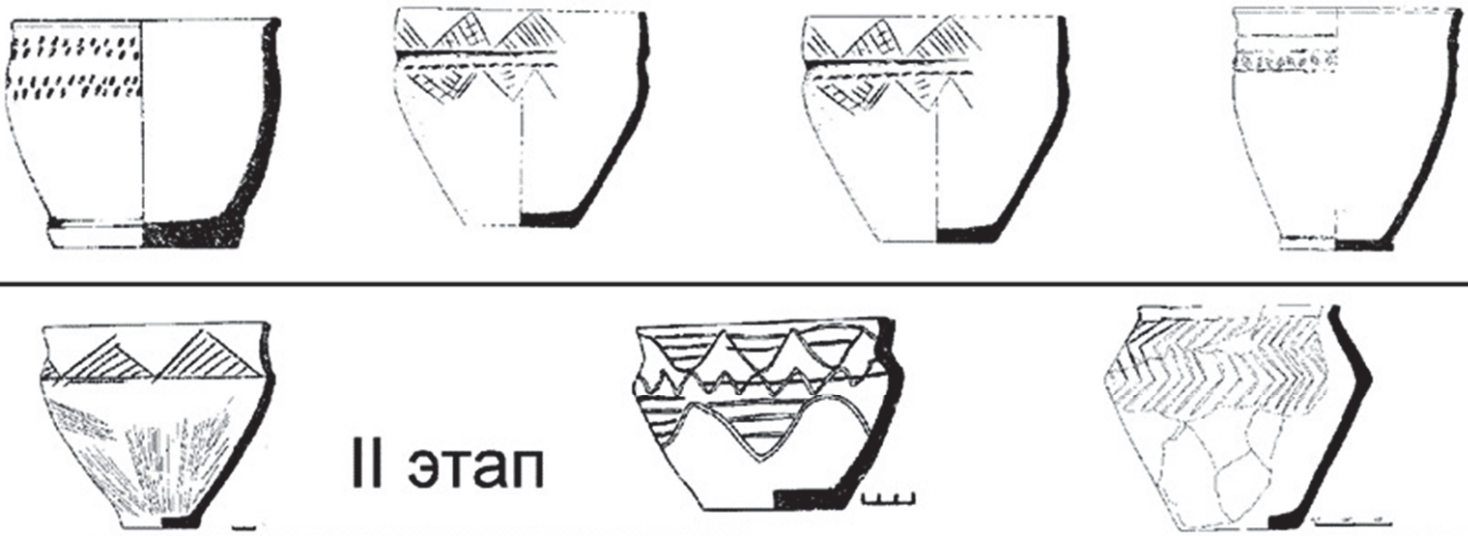

ІІ этап
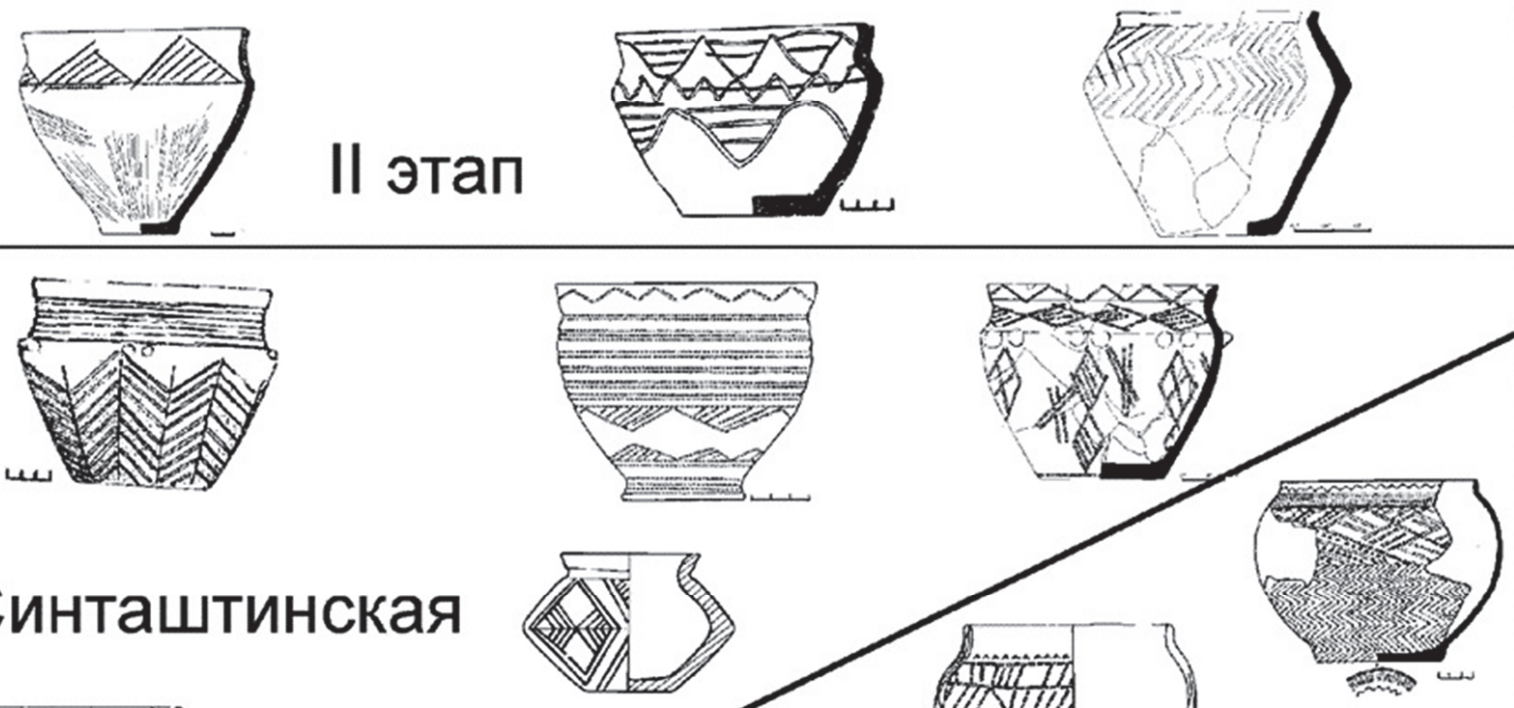

Синташтинская
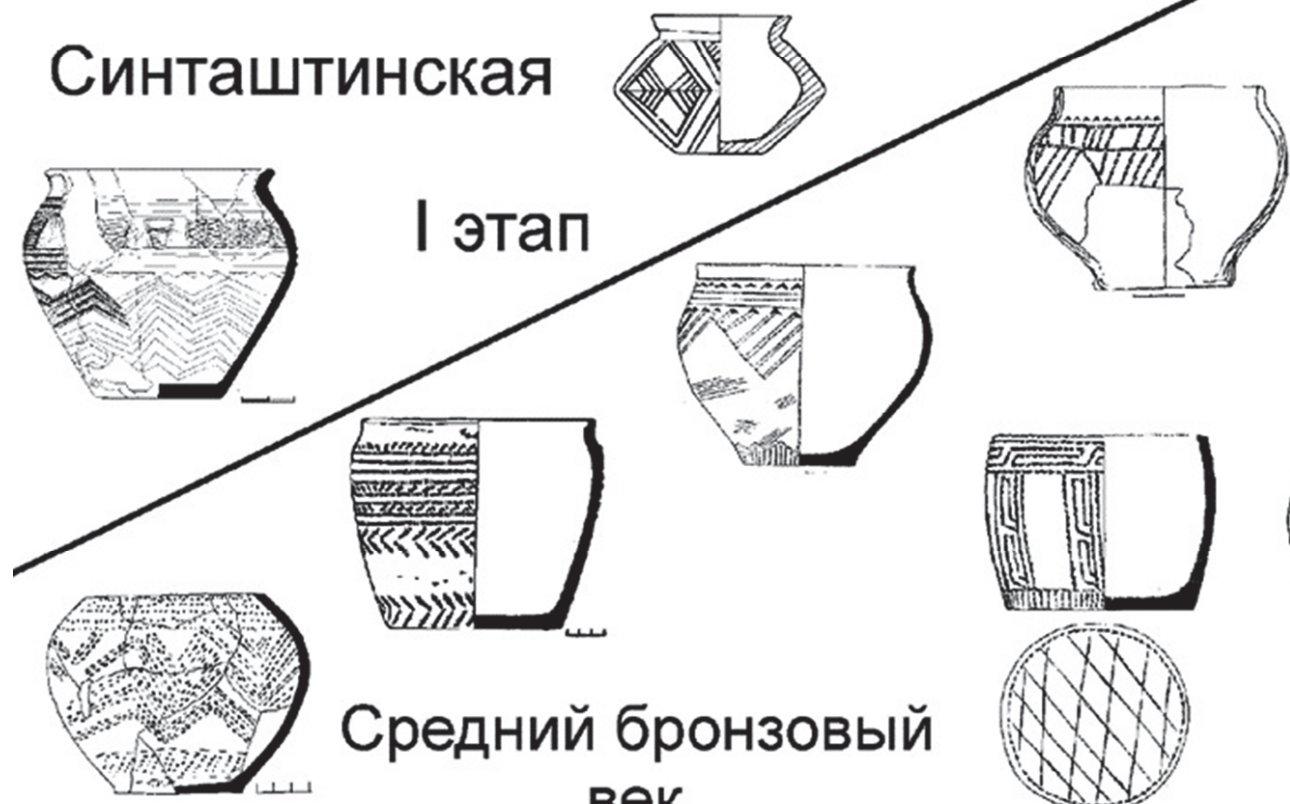

\section{Средний бронзовый} век
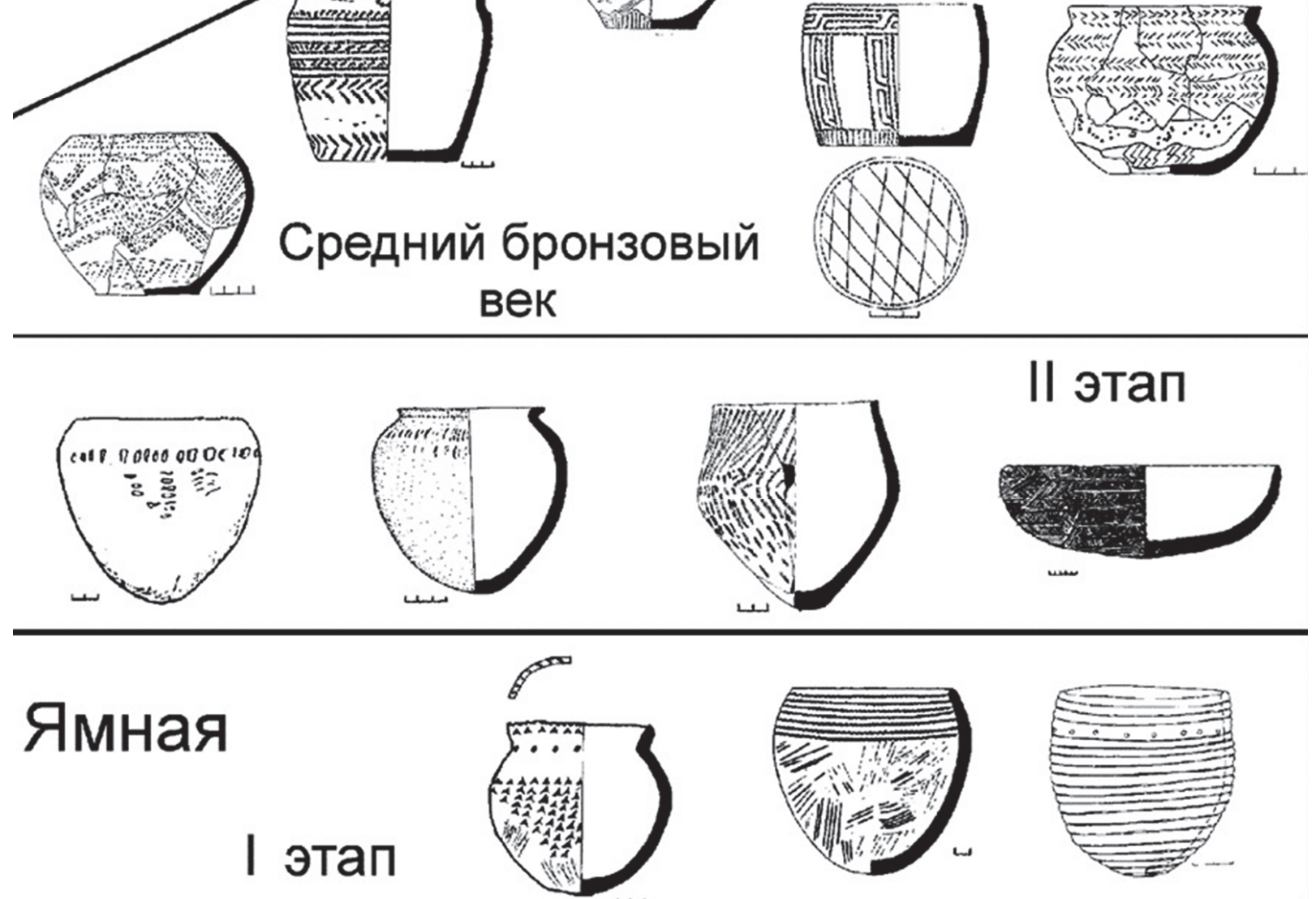

Рисунок 1 - Схема развития и соотношения керамики культур эпохи бронзы степного Приуралья 


\section{Ранняя срубная}
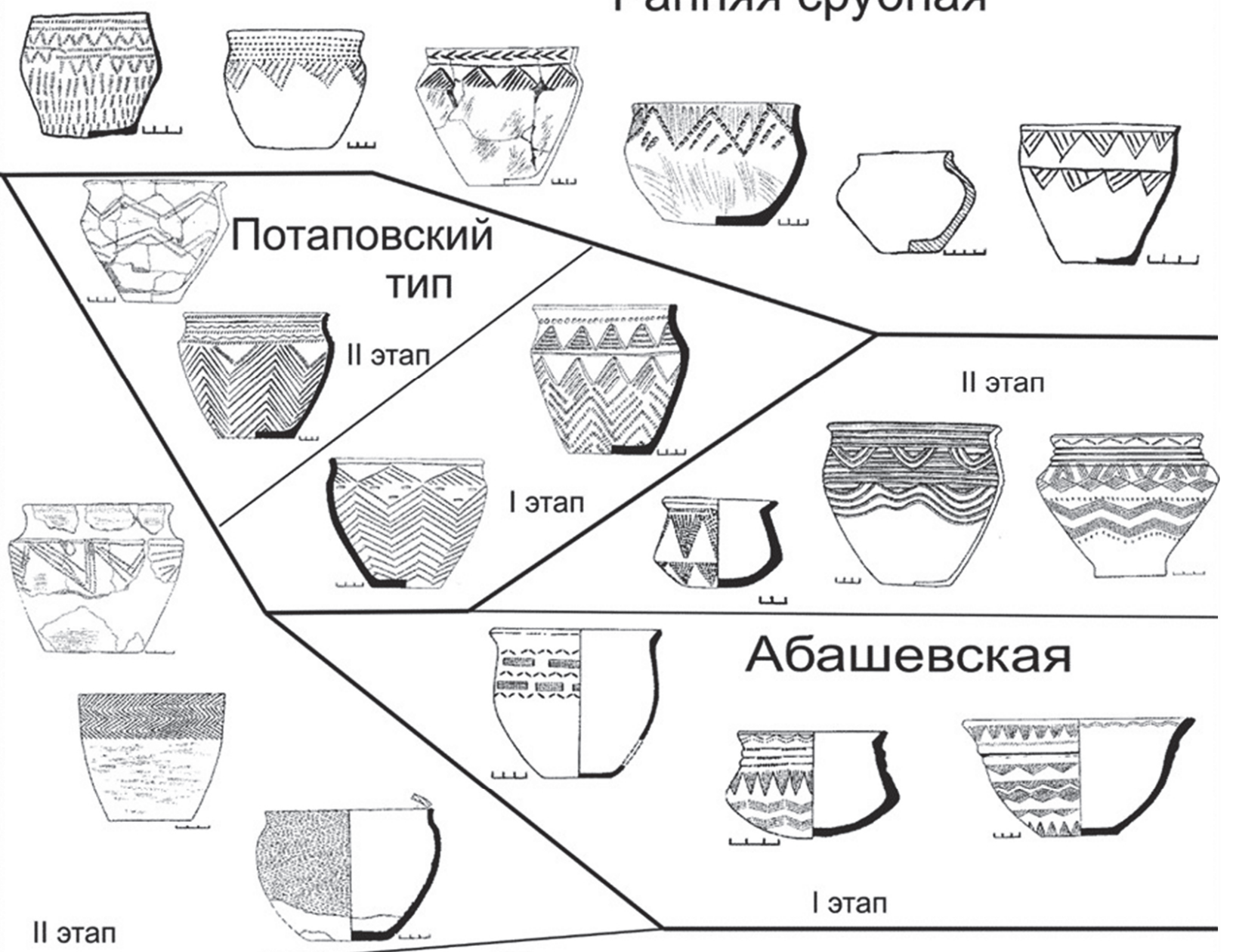

II этап

\section{Полтавкинская}
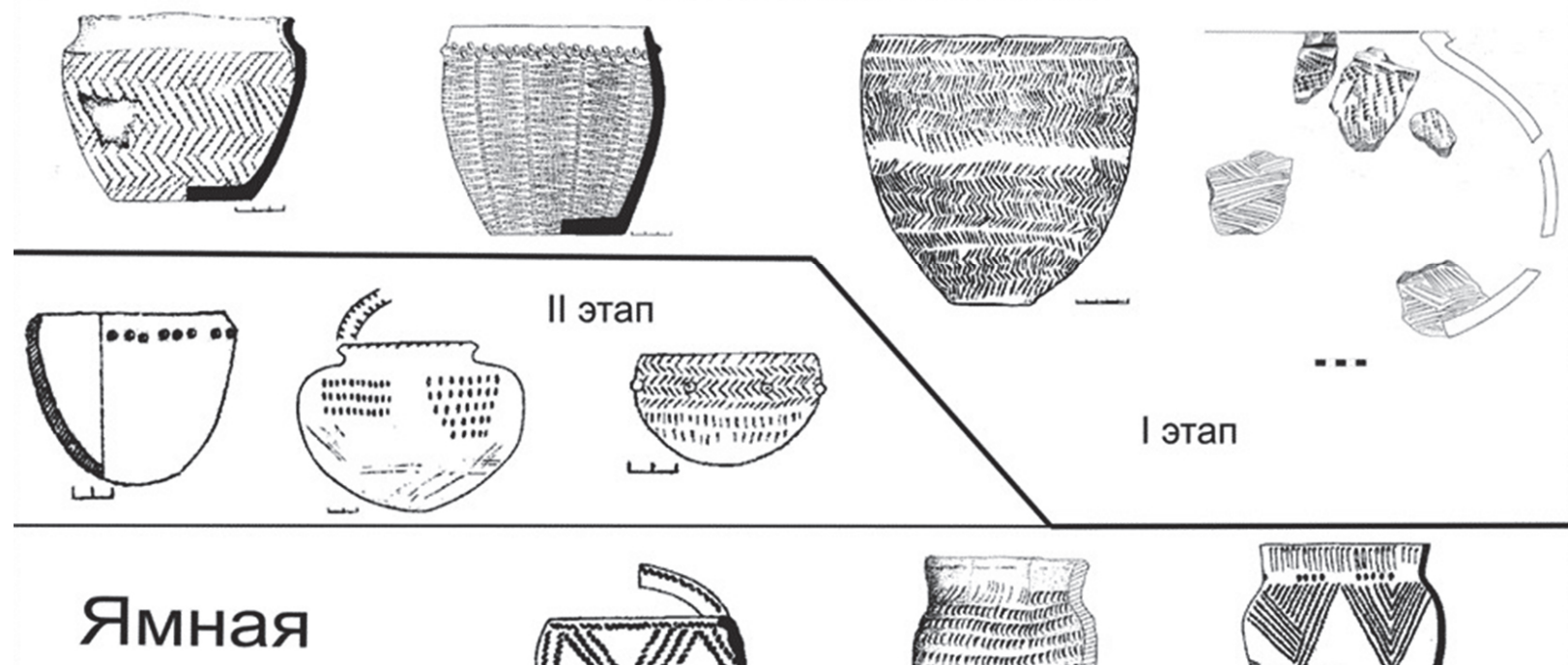

І этап
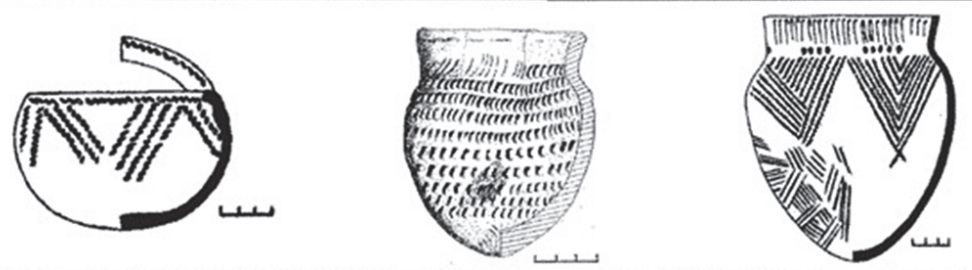

Рисунок 2 - Схема развития и соотношения культур эпохи бронзы лесостепи Волго-Уральского междуречья

Генезис керамического комплекса срубной культуры связан с потаповскими и синташтинскими группами, в меньшей степени с абашевскими и совсем незначительно, в больше степени опосредованно, с полтавкинскими. На облик раннесрубной керамики вплоть до Поволжья оказали влияние и раннеалакульские традиции, формирующиеся параллельно на близкой основе, а также южные - среднеазиатские. Керамика памятников бережновского типа собственного стандарта не имеет. Покровские признаки в разной степени представлены в различных памятниках. Дальнейшее развитие комплекса связано со стандартизацией и упрощением и проходило во взаимодействии с восточными андроновскими гончарами, которые постепенно усиливали свое влияние. 
Преемственность определенных традиций формообразования прослеживается с эпохи ранней бронзы по линии: ямная - полтавкинская - потаповская/синташтинская - срубная/алакульская (сосуды баночной, слабопрофилированной форм, горшки с расширенным туловом, сосуды с уступом, идентичные варианты конструкций форм). Преобладающая часть сосудов этих типов и конструкций имеет местные корни. Инокультурные влияния, в основном в виде компонентов, усложняли волго-уральские стереотипы, дестабилизировали навыки формообразования, придавали особые черты керамике и способствовали сложению новых культур в периоды активизации взаимодействия населения. В частности, совершенно особый колорит керамическим комплексам рубежа средней бронзы придало взаимодействие с появившейся на Южном Урале абашевской культурой, формы и декор которой отличались яркой спецификой и не были напрямую связаны с наследием ямных племен. До развитого этапа позднего бронзового века керамические формы в целом развивались в направлении их усложнения и стандартизации. Прослеживается определенная эволюционность на фоне смешения традиций разных групп населения и применения разных навыков труда. На развитом этапе срубной культуры проявилась тенденция к упрощению форм, сокращается число конструкций и типов.

Расцветом конструктивного разнообразия керамики и типообразования явился конец средней начало поздней бронзы, что отражают керамические традиции потаповских, синташтинских, некоторых абашевских и раннесрубных памятников. Именно в этот период распространяются наиболее сложные формы и появляются новые конструкции. Наиболее сложна и орнаментация керамики указанных культур. При общей близости традиций Заволжья и Приуралья, самые сложные, нестандартные варианты глиняной посуды фиксируются в пограничье ландшафтных зон степи и лесостепи.

У керамики потаповского, синташтинского типа и срубной культуры формообразующими являются верхние части сосудов. Невзирая на развитие стандартизации конструкций типов, когда у каждого типа есть доминирующие варианты его структуры, навыки изготовления одних и тех же верхних частей форм чрезвычайно вариабельны. Пропорции нижних частей и навыки их лепки стабильны. Выявленная закономерность не характерна для керамики других проанализированных комплексов ранней - средней бронзы, где отмечается значительная вариабельность в пропорциях и формах тулова и придонной части при различном состоянии навыков их создания.

Изменение традиций орнаментации четко фиксируется эпохально:

1) ранний бронзовый век - орнаментация простыми орнаментами верхних частей сосудов: прямыми линиями, вдавлениями, насечками, значительное число недекорированной посуды, отражающей ограниченную роль орнамента в традиции;

2) первая половина эпохи средней бронзы - орнаментация преобладающей поверхности сосудов «елкой», «шагающей гребенкой» на фоне сохранения предшествующих традиций (кроме абашевской куль- туры, наследовавшей лесные геометрические традиции), усиление значимости декора в традиции;

3) вторая половина среднего бронзового века эклектичность, расцвет геометрических, меандровых, ковровых, рельефных орнаментов, покрывающих большую часть сосуда при сохранении «елочной» традиции;

4) поздняя бронза - постепенное затухание «елочной» традиции, исчезновение «шагающей гребенки», упрощение декора, орнаментация верхней части сосудов зигзагами, треугольниками, насечками, меандрами, резкое снижение роли орнамента в культурной традиции определенных памятников.

Во все периоды декор наносился в основном различными вариантами зубчатого штампа и прочерчиванием. Во всех изучаемых культурах, начиная с ранней бронзы, существовали общие традиции по созданию некоторых орнаментальных образов, однако они были представлены в разных количественных соотношениях и сочетаниях. Наиболее выразительные следующие: горизонтальная «елка», ряды оттисков штампа, вдавлений или насечек, одинарный зигзаг, заполненный треугольник, прямые горизонтальные линии.

Около $50 \%$, а иногда и более, орнаментальных образов/мотивов всех культур встречается единично и является локальными. Нередко это дополнительные мотивы. Обычно они вписываются в общий стиль орнаментики, демонстрируя, возможно, творчество гончаров, но в то же время иногда отражают инокультурные влияния. Особенно рельефно это демонстрирует керамика абашевской культуры. Важная роль декорирования в культурной традиции, значимость орнамента наиболее рельефно отражена в полтавкинских, абашевских, а также в потаповских и синташтинских материалах первого этапа, то есть в керамических комплексах культур средней бронзы. Это проявилось в существенном доминировании орнаментированной, причем в основном достаточно богато, с сочетаниями разных стилей и технологий, посуды, по сравнению с недекорированной.

На развитом этапе срубной культуры формы и декор посуды стандартизируются, значительно сокращается набор форм и несколько уменьшается число образов. Это отражает стабилизацию, выработку определенного стандарта. Производство становится более массовым и упрощенно стандартизированным. Значимость орнаментации в культурной традиции резко снижается, приближаясь по показателям к раннему бронзовому веку. Это может свидетельствовать об исчезновении определенных стандартов декорирования и появлении традиции неорнаментированной керамики.

Преемственность с эпохой ранней бронзы подтверждается и по некоторым важным параметрам технологии изготовления сосудов, продемонстрированной специалистами в данном направлении [7, c. 139-143]. Это касается таких важных данных, как сохранение у некоторых групп уровня протогончарного производства, использование глин и глиноподобного сырья, примеси раковины и шамота, некоторых способов лепки, обработки поверхности заглаживанием и штриховкой, обжига сосудов и т.д. 
Таким образом, в генезисе керамических комплексов эпохи бронзы всегда участвовали местные волго-уральские группы населения, но их вклад в формирование последующих традиций был не равноценным, различным по масштабам и значимости и неравномерно проявлялся в технологии, формообразовании и орнаментации, выражаясь в локальной специфике регионов и определенных памятников. Население соседних территорий, особенно степное, периодически вовлекалось в систему взаимодействия, но направления и интенсивность контактов корректировались в зависимости от суммы факторов. Взаимодействие местных и соседних, в основном культурно близких групп, усложнялось дальними связями, которые фиксируются в резких изменениях некоторых традиций, дестабилизации навыков формообразования или появлении черт, совершенно несвойственных для предшествующего времени, что способствовало выработке новых культурных стереотипов. Вовлечение населения северной части Волго-Уралья в систему дальних связей отражено в периодическом распространении некоторых его традиций на значительные расстояния, что особенно четко фиксируется в эпоху ранней бронзы и поздней бронзы.

При сравнении степени близости глиняной посуды сопоставляемых культур по разным параметрам отмечено, что показатели наиболее «сильной» связи выявлены для пар: потаповская - срубная (от $86,7 \%$ $93,9 \%$ по орнаментации), потаповская - синташтинская (82\% по орнаментации и 79\% общий показатель), потаповская - алакульская (79\% по формам), абашевская - срубная (83,5\% близость орнаментальных образов), алакульская - срубная (80,02\% близость орнаментальных образов), алакульская - синташтинская (79,1\% по формам). Как правило, самые сильные связи складывались в отношении традиций декорирования, более быстро передаваемых, менее значимые по формам. Наиболее высокие показатели по формам прослежены по линии: потаповская - синташтинская - раннеалакульская, что подтверждает прямую связь комплексов не только в декорировании, но и формообразовании. Таким образом, близость означенных культур рубежа средней - поздней бронзы друг с другом наиболее очевидна. Значительно скромнее в общей системе выглядят абашевские и полтавкинские показатели, которые по отдельным параметрам и подтверждают связь культур, но в основном не превышают значения близости $66 \%-69 \%$, что оставляет поле для интерпретации.

Тем не менее показатель степени близости не следует абсолютизировать, так как, например, в случае сопоставления с полтавкинской керамикой сравниваются крупные и относительно синхронные керамические комплексы с разновременными единичными полтавкинскими. Соответственно и информация будет носить более общий характер сравнения культур в целом, а не связанных конкретных этапов.

Интересным результатом является установление уровня традиционности функциональных частей форм сосудов и навыков труда по их созданию. Ни в одной из исследованных культур сформированное состояние различных частей форм не является пре- обладающим - самый высокий показатель (49,6\%) на первом этапе абашевской культуры. В основном сформировано тулово, реже дно сосудов изучаемых культур. Второе место по сформированности занимает керамика Грачевского II и Утевского VI могильников потаповского типа. Таким образом, всегда происходило весьма сильное смешение традиций, когда применение традиционных навыков составляло в среднем только от $35 \%$ до $44 \%$ случаев. Более высокие значения редки. Указанные относительно высокие для эпохи бронзы показатели свидетельствуют о максимальной стабильности традиций, имевшей место в эпоху бронзы изучаемого региона. Причем в первую очередь это относится к абашевской культу$\mathrm{pe}$, генезис которой с изучаемым регионом пока не связывается.

Интересно, что в изучаемых культурах части самых несложных форм порой чаще, чем части сложных форм, изготавливались гончарами с несформированными или частично сформированными навыками труда. Это позволяет предположить, что лепкой простых наиболее распространенных форм занимались менее опытные мастера (фиксируется и внешняя небрежность), а более сложные типы нередко отражают и более развитые навыки по их производству. В то же время наиболее простые универсальные формы характерны для всех культур и, составляя разную долю в выборках, производились, в отличие от многих сложных, исторически. Значительная часть функциональных частей пребывает в частично сформированном, несформированном, а иногда и переходном промежуточном состоянии. Выявление промежуточного нестабильного состояния в меньшей степени характерно для керамики раннеалакульских памятников, где функциональные части идентифицировались наиболее надежно. Переходное состояние в основном типично для частей, расположенных между туловом и губой. Обычно данная часть характеризуется неопределенным статусом между плечом и предплечьем, не вполне ясное состояние сформированности характерно для такой мелкой части, как губа (верхнее окончание сосуда), заключения о них нередко весьма условны. Дно нередко пребывает в спорном состоянии между традиционным и частично традиционным. Сосуды, у которых все, а не некоторые части традиционны, составляют крайне незначительное количество. Следовательно, производство в основном было нестабильным и гончары часто переходили на изготовление новых форм или частей сосудов. Это может объясняться и постоянным смешением традиций в контактном культурно-мозаичном регионе пограничья степи и лесостепи: чем ближе к югу, тем меньше традиционных частей форм. Велико и конструктивное разнообразие основных типов керамики.

На протяжении бронзового века меняется и значимость керамики в обряде. В раннем и начале среднего бронзового века только 20-25\% курганов содержат глиняную посуду, при этом $8-11 \%$ керамики фиксируется за пределами погребений. По сравнению с эпохой энеолита чувствуется явная дестабилизация традиций, определенная утрата навыков производства. Роль керамики в обряде, как, впрочем, и 
другого инвентаря, невелика. Ситуация эта сохраняется до развитого этапа полтавкинской культуры. Во второй половине среднего бронзового века керамика становится обязательным атрибутом захоронений. Ее роль в обряде чрезвычайно высока, вырабатываются определенные стандарты производства.

Поселенческие материалы не противоречат результатам, полученным по погребальной керамике, но данные о них более лакунарны, так как не представляют цепочки последовательности всех культур (отсутствуют достоверные поселения культур: ямной, полтавкинской, синташтинской, потаповской, имеются только отдельные фрагменты похожих сосудов) и не дают возможности применения соответствующих методов. Поселенческая керамика абашевской и срубной культур соответствует типам форм и орнаментике погребальных сосудов, используемых в ритуале, но более крупна и стандартна [8, с. 1-133]. Вариабельность типов на поселениях не столь велика, некоторые формы вообще отсутствуют или представлены единично. Во многих памятниках более беден и стандартен декор, технология его нанесения. Значительная часть поселенческих материалов более традиционна, чем погребальные, и не отражает всего выявленного спектра культурных связей. Многие поселения абашевской культуры содержат синкретическую «абашевско-синташтинскую» керамику и единичные фрагменты собственно синташтинско-потаповской посуды. На некоторых после абашевской следует срубная керамика. Связь абашевской и срубной культур на бытовых памятниках была более сложной, чем простое перерастание, имеются поселения, как демонстрирующие преемственность, так и не показывающие их непосредственной связи, в частности Чишминское, где срубный слой отделен от абашевского прослойкой [9, с. 209-212]. Это соответствует выводу, сделанному при анализе погребений: нельзя утверждать, что все население абашевской культуры приняло участие в сложении срубной, скорее, речь идет о некоторых группах.

Следует отметить, что многие из данных о формировании и взаимодействии культур в определенной мере подтверждаются и антропологическими материалами [10, с. 133-167; 11, с. 112-131]. Это относится к контактам с северными лесными и восточными группами в эпоху ранней - средней бронзы, в том числе к влиянию культур «гребенчатого геометризма» на абашевскую и синташтинскую, к связям с южными и юго-западными группами населения и населением Доно-Волжского степного междуречья, фиксирующимися в различной мере фактически во все эпохи. Важно и то, что во все периоды эпохи бронзы и практически во всех культурах фиксируется местный уральский антропологический компонент. Очевидным расхождением является дискуссионная антропологическая связь потаповского и срубного населения, что оставляет почву для обсуждения преемственности населения и материальной культуры. Однако и в этом случае участие нового южноевропеоидного населения в сложении срубной культуры подтверждается резким распространением неорнаментированной керамики и специфичными формами.
Подчеркнем, что данные результаты касаются в первую очередь генезиса керамических традиций, которые могут не совпадать с итогами изучения других категорий инвентаря и обряда. Однако эти выводы очень значимы для реконструкции культурогенеза в целом, так как многие археологические культуры были выделены в значительной степени именно исходя из специфики их глиняной посуды, отражающей как преемственность, так и смешение населения.

\section{СПИСОК ЛИТЕРАТУРЫ:}

1. Мочалов О.Д. Керамика погребальных памятников эпохи бронзы лесостепи Волго-Уральского междуречья. Самара: Изд-во СГПУ, 2008. 252 с.

2. Бобринский А.А. Функциональные части в составе емкостей глиняной посуды // Проблемы изучения археологической керамики. Куйбышев: Изд-во КГУ, 1988. С. 5-22.

3. Гошев И.С. Правила описания сосудов // Теория и прикладные методы в археологии. Саратов: Изд-во СарГУ, 1994. С. 25-60.

4. Волкова Е.В. Гончарство фатьяновских племен. М.: Изд-во «Наука», 1996. 122 с.

5. Генинг В.Ф. Древняя керамика. Методы и программы исследования в археологии. Киев: Изд-во «Наукова Думка», 1992. 188 с.

6. Ткачев В.В. Степи Южного Приуралья и Западного Казахстана на рубеже эпох средней и поздней бронзы. Актобе: Изд-во «Актюбинский областной центр истории, этнографии и антропологии», 2007. 384 c.

7. Васильева И.Н., Салугина Н.П. Некоторые итоги изучения древнего и средневекового гончарства в Самарском Поволжье // 40 лет Средневолжской археологической экспедиции. Краеведческие записки. Вып. XV. Самара: Изд-во ООО «Офорт», 2010. C. $135-155$.

8. Горбунов В.С. Поселенческие памятники бронзового века в лесостепном Приуралье. Куйбышев: Изд-во КГПИ, 1989. 134 с.

9. Морозов Ю.А. Материалы абашевской культуры на срубных памятниках Башкирского Приуралья // Абашевская культурно-историческая общность: истоки, развитие, наследие: материалы международной научной конференции. Чебоксары: Изд-во «Чувашский государственный институт гуманитарных наук», 2003. С. 209-212.

10. Хохлов А.А. Демографические процессы в северной половине Волго-Уралья в эпохи энеолитабронзы // Кони, колесницы и колесничие степей Евразии. Екатеринбург-Самара-Донецк: Изд-во «Институт экологии растений и животных УроРАН», 2010. C. 133-167.

11. Хохлов А.А. О происхождении и дальнейшем развитии физического типа носителей синташтинскопотаповского круга культур // Аркаим - Синташта: древнее наследие Южного Урала. К 70-летию Г.Б. Здановича. Часть ІІ. Челябинск: Изд-во «ЧелГУ, 2010. C. 112-131.

Статья публикуется при поддержске гранта РГНФ, проект № 15-11-663008 и в рамках выполнения Государственного задания Минобрнауки РФ № 33.1395.2014/к «Исторические истоки взаимодействия и толерантности народов Поволжья». 


\title{
TRADITIONS OF CERAMIC SHAPE'S MAKING AND ORNAMENTATION FOR THE POPULATION OF BRONZE AGE OF NORTHERN PART OF VOLGA-URAL: ABOUT DOMESTIC DEVELOPMENT DIRECTION
}

(C) 2016

O.D. Mochalov, doctor of historical sciences, rector, professor of the Chair of Domestic History and Archaeology Samara State University of Social Sciences and Education, Samara (Russia)

\begin{abstract}
The Volga-Urals population always took part in forming ceramic complexes of the Bronze Age. However the contribution they made to the genesis of the following traditions was unequal, differed in its extent and importance and was unequally revealed in technology, form making and decorating. All these factors could be traced the local specifics and particular artifacts. The neighboring population, especially the steppe one, was involved in the cooperation system, but the directions and intensity of contacts were corrected according to different factors and characteristics of the historic periods. The cooperation between the local and neighboring groups culturally close to each other was complicated by long distance communications, which resulted in drastic changes in some traditions, destabilization of skills at form making, emergence of some characteristics irrelevant to the previous times. It caused new cultural standards. The involvement of the northern Volga-Urals population in the system of long distance communications found its reflection in the wide expansion of traditions; especially in the early and late Bronze Age. The paper contains not only traditional typological results but also the results of special methods appliance of ceramic analysis: reveal of natural structure of forms, structural analysis of ornament, definition of the degree of proximity of ceramic complexes.

Keywords: Volga-Urals interfluve; Bronze Age; forest-steppe and the north of steppe; form and ornament of ceramics; typology; natural structure of forms; skills at form making; structural analysis of ornament; degree of proximity; Yamnaya culture; Poltavkinskaya culture; Potapovskiy type; Abashevo culture; Sintashta culture.
\end{abstract}

УДК 94 (367) : 929.5

\section{БРАК КОНСТАНТИНА МИХАЙЛОВИЧА И СОФЬИ ЮРЬЕВНЫ И ЕГО МЕСТО В ПОЛИТИЧЕСКИХ ОТНОШЕНИЯХ МОСКВЫ И ТВЕРИ В XIV ВЕКЕ} (C) 2016

С.Н. Абуков, кандидат исторических наук, старший преподаватель кафедры историографии, источниковедения, археологии и методики преподавания истории Донецкий национальный университет, Донеик (Донеикая Народная Республика)

Аннотация. Статья посвящена браку 1320 г. князя Константина Михайловича и княжны Софьи Юрьевны в драматический период московско-тверских отношений. Этот семейный альянс между Москвой и Тверью, который открыл череду браков между двумя правящими династиями в XIV-XV вв., не получил комплексного исследования со стороны историков. Автор анализирует обстоятельства и причины его заключения, а также определяет его влияние на политические отношения на Руси в XIV в. Отмечается, что родственный союз имел целью ослабить единство тверских князей. В статье уделено внимание спорному в научной литературе вопросу происхождения по материнской линии сыновей правившего в XIV в. в Твери князя Константина Михайловича, женатого дважды. Автор, сделав анализ имеющихся данных, устанавливает старшинство Константиновичей от разных браков отца и их предполагаемых матерей. Семейный конфликт между тверскими князьями имел значительные политические последствия для истории Тверского княжества и ее дальнейшей судьбы в борьбы с Москвой. В статье прослеживается спорная генеалогия их потомства. Отрицается, что дворяне Порошины могут быть потомками тверских князей, утративших титул.

Ключевые слова: Москва; Тверь; Кострома; Константин Михайлович; Софья Юрьевна; Юрий Данилович; Еремей Константинович; Семен Константинович; Дорогобужские; Чернятинские; Порошины; князь; брак; жена; сын; завещание; княжество; власть; политические отношения; происхождение; старшинство; владение.

Первая треть XIV в. - период длительной и жестокой борьбы в Северо-восточной Руси между двумя крупнейшими политическими центрами: Москвой и Тверью за титул великого князя владимирского, а фактически - за лидерство среди русских земель. Долгое время именно в споре Москвы и Твери происходила основная линия противостояния за гегемонию. Это был сложный процесс взаимодействия двух княжеств, где периоды смертельной вражды сменялись поисками компромисса и примирения. Браки представителей обоих княжеских линий являлись важнейшим индикатором колебания маятника политических отношений потомков Даниила Московского и Михаила Тверского. С другой стороны они становились элементом продолжения политики, только другими методами, не менее действенными, чем меч или договор.

Первым в серии браков, заключнных между представителями Тверского и Московского княжеских домов, стал брак 1320 г. третьего сына убитого в Орде Михаила Ярославича Тверского Константина с троюродной племянницей, дочерью великого князя владимирского и московского Юрия Даниловича Софьей. Это известие содержится в Рогожском летописце («Въ лето 6828 оженися князь Костянтинъ Михаилович [ь] оу великаго князя Юрїа Софїею, вен- 